\title{
USO DE INFORMAÇÕES CONTÁBEIS PELO MOVIMENTO SINDICAL DOS BANCÁRIOS'
}

\author{
Paulo Frederico Homero Junior ${ }^{2}$ \\ Bruno Meirelles Salotti ${ }^{3}$
}

\begin{abstract}
Resumo: O objetivo deste trabalho foi investigar a utilidade, para o movimento sindical dos bancários, dos relatórios publicados pelos bancos brasileiros. Para tanto, empregamos técnicas de análise de conteúdo para identificar e classificar o uso de informações rastreáveis nestes relatórios em matérias publicadas durante 2012 no jornal Folha Bancária, principal meio de comunicação do Sindicato dos Bancários e Financiários de São Paulo, Osasco e Região. Identificamos 964 ocorrências, que se concentram nas matérias de maior destaque do jornal e durante o período das negociações coletivas com os representantes patronais. Lucro líquido, composição da força de trabalho, remuneração dos administradores, operações de crédito e provisão para créditos de liquidação duvidosa são os temas citados com maior frequência. Há um predomínio do uso estratégico de tais informações, que são empregadas para justificar as demandas do sindicato. Nossos resultados indicam que as informações contábeis podem ser utilizadas de modo estratégico ou contestatório pelos sindicatos, não sendo ferramentas exclusivas dos administradores.
\end{abstract}

Palavras-chave: Análise de Conteúdo. Demonstrações Financeiras. Negociações Coletivas. Sindicalismo.

\footnotetext{
'Uma versão prévia deste artigo, sob o título Usefulness of the financial statements published by Brazilian banks to the bank workers' union movement, foi apresentada em julho de 2014 na Critical Perspectives on Accounting Conference, na cidade de Toronto, no Canadá

2E-mail: paulo.junior@usp.br - Universidade de São Paulo.

${ }^{3}$ E-mail: brunofea@usp.br - Universidade de São Paulo 


\title{
USE OF ACCOUNTING INFORMATION BY THE UNION MOVEMENT OF BANK WORKERS
}

\begin{abstract}
The objective of this work was to investigate the usefulness, to the unionist movement of bank workers, of the reports published by Brazilian banks. For that, we employed techniques of content analysis to identify and classify the use of pieces of information which could be tracked down to these reports in news published during 2012 in the newspaper Folha Bancária, the main medium of communication of the São Paulo Bank Workers Trade Union. We identified 964 occurrences, which are concentrated in the more prominent news within the newspaper and during the period of collective bargaining with employers' representatives. Net income, work force composition, management remuneration, bank loans, and allowance for bad debts are the more frequently cited themes. There is a predominance of a strategic use of these pieces of information, which are employed to justify the demands of the union. Our results indicate that accounting information can be used in either a strategic or an adversarial way by unions, not being a tool exclusively in service for management.
\end{abstract}

Keywords: Content Analysis. Financial Reports. Collective Bargaining. Unionism. 


\section{INTRODUÇÃO}

$\mathrm{D}$ efinições sobre os propósitos das demonstrações financeiras em termos de utilidade à tomada de decisões econômicas são item recorrente tanto nas normas contábeis quanto nos capítulos iniciais dos livros de introdução à contabilidade. No entanto, a ideia de que as demonstrações financeiras devam apresentar informações úteis a seus usuários se originou recentemente, nos Estados Unidos, tendo ganhado força apenas a partir da década de 1960 (Hendriksen \& Van Breda, 2007). Até então, as práticas contábeis eram definidas não em função da utilidade das informações que produziriam para os tomadores de decisões econômicas, mas sim de acordo com sua aderência a convenções contábeis como conservadorismo, consistência, custo histórico e regime de competência, sob a premissa de que demonstrações financeiras preparadas de acordo com tais convenções seriam obviamente úteis (Young, 2006).

No entanto, a ligação entre a contabilidade e a tomada de decisões tem sido mais presumida do que descrita (Burchell, Clubb, Hopwood, Hughes, \& Nahapiet, 1980), e o enfoque nas necessidades dos usuários das demonstrações financeiras acarreta algumas dificuldades: Quais usuários considerar? Até que ponto os objetivos de usuários diferentes são semelhantes? (Hendriksen \& Van Breda, 2007).

Tendo em vista o pouco conhecimento da comunidade contábil sobre os processos decisórios dos usuários das demonstrações financeiras, construiu-se uma ideia abstrata a respeito destes usuários, derivada de modelos econômicos e financeiros, e não de vontades expressas por pessoas reais. Segundo Young (2006), esta estreita conexão da contabilidade a um tomador de decisões econômicas na condição de investidor/credor limita severamente as possíveis relações de accountability que poderiam ser ensejadas e reportadas pelas demonstrações financeiras.

Dado o enfoque predominante na literatura contábil aos interesses de administradores, investidores e credores, pouco se conhece a respeito das necessidades e dos modelos decisórios dos demais usuários das demonstrações financeiras. E como lembra ludícibus (2004, p. 25), "enquanto isso não for conseguido, não poderemos atender igualmente bem, em todo e qualquer tempo, a todos os usuários".

Dentre estes demais usuários, nos despertou curiosidade a situação dos trabalhadores. Dependendo das organizações para garantir sua subsistência, dificilmente se encontrarão em condições de imporem a elas o dever de lhes prestar informações. Contudo, justamente por terem sua subsistência associada às organizações, acreditamos ser razoável supor que eles tenham interesse em obter informações a respeito delas, e que as demonstrações financeiras sejam um dos possíveis canais para que as obtenham. Mas será que as demonstrações financeiras atualmente publicadas pelas organizações são úteis aos trabalhadores? Partindo desta inquietação, decidimos investigar o seguinte problema: De que modos os relatórios publicados pelos bancos brasileiros são utilizados pelos representantes do movimento sindical dos bancários?

Com isso, pretendemos ampliar o entendimento de como as informações contidas nestes relatórios são processadas pelos sindicalistas e, por extensão, pelos bancários brasileiros. Em que pese o caráter exploratório de nosso estudo, esperamos contribuir para que a investigação dos papeis que a informação contábil desempenha passe a considerar contextos sociais mais amplos do que os que têm sido abordados tradicionalmente pela comunidade acadêmica nacional. 
O artigo prossegue da seguinte maneira: na Seção 2, descrevemos o processo de construção de nossa pesquisa, explicitando as escolhas metodológicas que fizemos. A Seção 3 apresenta uma revisão da literatura pertinente a nosso estudo, incluindo um modelo comportamental que descreve as negociações coletivas e textos sobre as relações entre a contabilidade e o movimento sindical. Na Seção 4 apresentamos e discutimos nossos resultados, e a Seção 5 é dedicada a nossas conclusões.

\section{CONSTRUÇÃO DA PESQUISA}

Dado nosso interesse em estudar a utilidade das demonstrações financeiras para os trabalhadores, optamos por estudar o uso que delas é feito pelo movimento sindical. Em que pese o fato de os sindicatos estarem sujeitos a uma dinâmica interna de relações de poder, que por vezes pode levar seus dirigentes a não agir de acordo com os interesses da base de representação ou, pelo menos, não os da maioria dela, ainda assim entendemos ser uma opção plausível, e a que se mostrou mais viável para a condução de nosso estudo.

Feita esta escolha, optamos também por restringir nosso estudo ao setor bancário brasileiro, no qual identificamos algumas características que julgamos favoráveis a nossa pesquisa. Primeiramente, trata-se de um setor de evidente importância na economia brasileira, que ao final de 2011 empregava cerca de 497 mil trabalhadores (Fontes, Macedo, \& Sanches, 2013), e que concentra poder não apenas econômico, mas também sociopolítico (Minella, 2007).

Além disso, as demonstrações financeiras dos bancos brasileiros são publicadas e facilmente acessíveis através dos sítios eletrônicos do Banco Central do Brasil (BCB) e, no caso dos de capital aberto, da Comissão de Valores Mobiliários (CVM), enquanto em muitos outros setores é considerável o número de empresas que não divulgam suas demonstrações financeiras. E como a lide com informações financeiras é parte da própria natureza das atividades profissionais da categoria, acreditamos que isto a torne mais propensa a utilizá-las também nas atividades sindicais, como sugerem evidências obtidas por Gomes (1998).

A categoria dos bancários possui uma longa tradição de organização sindical: o movimento teve início em 1923, quando foi criada a Associação dos Funcionários de Bancos de São Paulo, e a primeira Federação Nacional de Bancários foi criada em 1935, contando com a participação dos 23 sindicatos de bancários então existentes no país (Canêdo, 1986). Desde 1988, as negociações coletivas com os bancos são conduzidas nacionalmente: os encontros ocorrem na cidade de São Paulo, sede da Federação Nacional dos Bancos (FENABAN), entidade patronal, e da Confederação dos Trabalhadores do Ramo Financeiro (CONTRAF), entidade de maior representatividade da categoria (Amorim \& Huertas, 2011). Desta maneira, é possível coletar evidências em relação aos processos de negociação coletiva dos bancários através de um menor número de fontes do que seriam necessárias para obter abrangência semelhante em relação a categorias com negociações descentralizadas.

Assim, as evidências que analisamos nesta pesquisa foram coletadas a partir da Folha Bancária, principal e mais antigo veículo de comunicação do Sindicato dos Bancários e Financiários de São Paulo, Osasco e Região, que ao final de 2011 concentrava em sua base de representação cerca de 28,6\% de toda a categoria no Brasil (Fontes et al., 2013), tendo papel fundamental na condução da campanha nacional unificada. Analisamos as edições de números 5.504 a 5.614 do jornal, abrangendo todo o ano de 2012. À época, a Folha Bancária tinha periodicidade mínima de duas edições semanais, tiragem de cem mil exemplares e distribuição em cerca de três mil locais de trabalho (Fontes et al., 2013).

Inicialmente, nossa intenção era mapear o uso de informações contábeis nas matérias do jornal, mas nos deparamos com uma grande dificuldade: como distinguir o que seriam ou não informações contá- 
beis? Na literatura, as definições que encontramos giravam em torno da definição dada pela Associação Americana de Contabilidade, em 1966, segundo a qual "a contabilidade é 'o processo de identificação, mensuração e comunicação de informação econômica para permitir a realização de julgamentos e decisões pelos usuários da informação"' (Hendriksen \& Van Breda, 2007, p. 79). Em que pese a ampla difusão deste conceito, entendemos que sua abrangência o torna muito pouco aplicável operacionalmente. A fim de contornar tal dificuldade, adotamos uma solução pragmática: consideramos em nosso levantamento aquelas informações que pudessem ser diretamente rastreadas em relatórios publicados pelos bancos e arquivados no $\mathrm{BCB}$ ou na $\mathrm{CVM}$, incluindo as demonstrações financeiras, os relatórios da administração, os formulários de referência, os relatórios de sustentabilidade, etc.

Para estudar as evidências coletadas, empregamos a análise de conteúdo, descrita por Bardin (2011) como um conjunto de técnicas de análise das comunicações. Segundo a autora, o processo de codificação, que corresponde à transformação dos dados brutos do texto, é composto por três etapas: (i) recorte - escolha das unidades; (ii) enumeração - escolha das regras de contagem; e (iii) classificação e agregação - escolha das categorias.

A codificação considera como elementos do texto as unidades de registro e as de contexto. Unidades de registro são as unidades de significação a codificar e correspondem ao segmento de conteúdo a ser considerado como base para a categorização e contagem frequencial, tais como palavra, tema, objeto ou referente, personagem, acontecimento, documento, etc. Unidades de contexto, por sua vez, servem de unidade de compreensão para codificar as unidades de registro, permitindo que se entendam as significações destas (Bardin, 2011).

O tipo de análise que efetuamos foi do tipo temática, identificando nos textos publicados na Folha Bancária o uso de informações que pudessem ser diretamente rastreadas nos relatórios publicados pelos bancos. Além disso, através de unidades de contexto, classificamos o uso de tais informações como consensual, estratégico ou contestatório, conforme definições propostas por McBarnet, Weston e Whelan (1993) e apresentadas na Seção 3.2.

\section{REVISÃO DE LITERATURA}

A primeira dificuldade com que nos deparamos ao iniciar nossa pesquisa foi a falta de referências ligadas ao tema. No Brasil, o trabalho de maior destaque que encontramos a respeito dos impactos das informações contábeis sobre as ações sindicais foi o de Gomes (1998). Na literatura de língua inglesa conseguimos identificar um maior número de obras que abordam as relações entre o mundo do trabalho e as informações contábeis produzidas pelas organizações, porém a maioria delas se refere aos anos 1980 e ao contexto do Reino Unido. Na Seção 3.2 apresentamos nossa revisão destas obras, mas antes disso descrevemos, na Seção 3.1, o modelo comportamental proposto por Walton e McKersie (1965) para descrever os processos de negociação coletiva, o qual serviu de referencial para muitas das obras que identificamos.

\subsection{MODELO COMPORTAMENTAL DE NEGOCIAÇÕES COLETIVAS}

Walton e McKersie (1965) propõem um modelo comportamental para descrever as negociações coletivas, classificando-as em quatro subprocessos que, segundo eles, descrevem a maioria dos comportamentos observados nestas negociações: 
- Negociações distributivas, que ensejam comportamentos competitivos cuja intenção é influenciar na divisão de recursos escassos;

- Negociações integrativas, em que os comportamentos visam solucionar problemas comuns a ambas as partes, ampliando os ganhos conjuntos disponíveis a ambas;

- Estruturação atitudinal, compreendendo as atividades de influência sobre as atitudes de cada parte em relação à outra;

- Negociações intraorganizacionais, relativas aos comportamentos que um negociador adota visando obter consenso interno na organização que representa.

Negociações distributivas são processos de soma zero, ou seja, os ganhos de uma parte são iguais às perdas incorridas pela outra. Nas negociações salariais, tomadas pelos autores como principal exemplo de negociação distributiva entre empresas e sindicatos, os ganhos e perdas das partes se restringem a um intervalo cujo limite inferior é dado pelo ponto que levaria os empregados a procurar novos empregos, e o limite superior, pelo ponto que levaria as empresas a mudar de ramo, buscando empregar mão de obra mais barata.

Já nas negociações integrativas, os interesses das partes convergem para a solução de problemas comuns. São situações onde ambas as partes obtêm ganhos em relação ao status quo prévio, ou onde ambas procuram por soluções que Ihes propiciem as menores perdas possíveis. Trata-se, basicamente, de um processo de solução de problemas que pode ser descrito em três passos: (i) identificação do problema; (ii) procura de soluções alternativas e avaliação de suas consequências; e (iii) ordenação de preferência entre as soluções e seleção de um curso de ação. Condições de saúde e segurança no trabalho são um exemplo de assunto em cuja negociação os interesses de empresas e sindicatos podem convergir.

A manutenção ou reestruturação das atitudes de uma parte em relação à outra faz parte do subprocesso de estruturação atitudinal. Segundo Walton e McKersie (1965), o padrão que prevalecerá em determinado relacionamento dependerá de fatores contextuais, de características das personalidades dos negociadores, das crenças sociais prevalecentes e dos processos de perpetuação ou de mudança do status quo. Estes padrões afetarão a administração dos acordos firmados, as agendas de negociação e seus respectivos resultados, e até mesmo a organização interna de cada uma das partes.

Por fim, o subprocesso das negociações intraorganizacionais diz respeito aos conflitos que ocorrem dentro de cada organização, e como elas chegam a um consenso sobre os objetivos e prioridades a serem adotados durante as negociações coletivas. Estes conflitos surgem em razão de diferenças de objetivos, de fatores emocionais e de percepções distintas, como mostra a Figura 1.

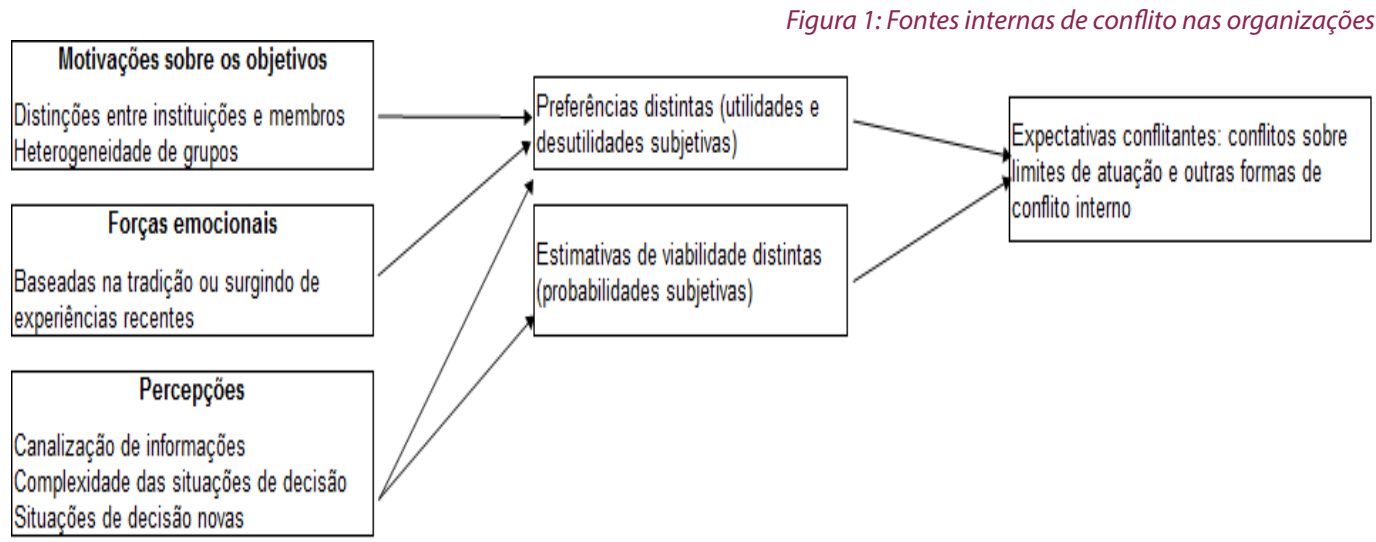


Embora tratem separadamente cada um destes subprocessos, Walton e McKersie (1965) insistem que todos eles são característicos das negociações coletivas. Uma estratégia de comprometimento intransigente com suas demandas iniciais, por exemplo, pode fortalecer um sindicato durante uma negociação distributiva, ao mesmo tempo que diminui suas possibilidades de ganho em negociações integrativas e prejudica o seu relacionamento com a empresa. Estratégias de comunicação aberta podem fortalecer negociações integrativas e melhorar os relacionamentos entre sindicatos e empresas, mas prejudicar a ambos nas negociações distributivas e serem mal vistas dentro de cada uma das organizações. Apenas o grau de confiança estabelecido entre as partes, segundo os autores, aparenta ser benéfico a elas em todos os subprocessos, propiciando maior efetividade às ameaças feitas durante negociações distributivas, incrementando os ganhos em negociações integrativas e facilitando os relacionamentos entre as partes e os intraorganizacionais.

\subsection{A CONTABILIDADE NOS PROCESSOS DE NEGOCIAÇÕES COLETIVAS}

Segundo Foley e Maunders (1977), um dos principais conceitos relacionados ao uso de informações contábeis nas negociações coletivas é o de capacidade de pagamento, e diversos indicadores contábeis acabam sendo utilizados para este fim, embora não sejam usualmente vistos por sindicalistas como um fator determinante nas negociações. Para os autores, a divulgação de informações contábeis não piora, necessariamente, a situação das organizações que as divulgam, e a decisão de efetuar ou não tal divulgação deveria ser tomada pela alta administração, que melhor poderia avaliar os efeitos de longo prazo desta política. Para os sindicatos, os autores destacam que estas informações podem servir como ferramenta de racionalização de suas demandas, a fim de influenciar as percepções do público em geral, do governo e de possíveis árbitros.

Para Craft (1981), três fatores influenciam a divulgação voluntária de informações contábeis pelas organizações aos sindicatos:

- Discricionariedade - relaciona-se ao poder de barganha da organização em relação ao sindicato, ou seja, sua capacidade de chegar a um acordo em seus próprios termos. Quanto maior for o poder de barganha da organização, maior será sua liberdade para escolher o quanto divulgar de informações além daquelas requeridas por lei;

- Necessidade - influenciada pelo grau de independência da organização nas negociações. Se a organização for uma habitual seguidora do padrão das negociações de seu setor, ou se for representada nas negociações por um sindicato patronal, menor será sua necessidade de divulgar informações contábeis aos sindicatos;

-Vontade - o desejo da administração em fornecer informações ao sindicato é afetado por diversos fatores, inclusive os dois já citados, mas decorre principalmente da natureza do relacionamento entre as partes. Relacionamentos mais (menos) conflituosos tendem a diminuir (aumentar) a vontade dos administradores de divulgar informações aos sindicatos.

Craft (1981) entende ser inapropriado sugerir que uma ampla divulgação de informações contábeis aos sindicatos seja uma política a ser adotada generalizadamente pelas organizações. Pelo contrário, o autor ressalta haver significante linha de pensamento entre sindicalistas e acadêmicos sustentando a necessidade de que sindicatos e administradores mantenham uma relação equidistante, a fim de que possam exercer adequadamente seus papéis. Assim, as políticas de divulgação de informações 
contábeis aos sindicatos tenderiam a uma zona de acomodação, na qual a quantidade e a utilidade das informações divulgadas aos sindicatos se manteriam em níveis intermediários.

Jackson-Cox, Thirkell, e McQueeney (1984), através de um estudo multicaso com 17 companhias britânicas, examinaram o papel da divulgação de informações contábeis no desenvolvimento das estratégias de negociação coletiva tanto das organizações quanto dos sindicatos. O principal fator de distinção identificado pelos autores entre as abordagens dos sindicatos foi a segmentação interna da força de trabalho em cada organização, com os sindicatos de trabalhadores das áreas administrativas (white collars) demonstrando maior interesse na obtenção e uso de informações contábeis do que os sindicatos de trabalhadores das áreas fabris (blue collars). Eles argumentam que o fornecimento de informações contábeis aos sindicatos lhes permite aumentar sua compreensão sobre a gestão das organizações e sua capacidade de perceber novos assuntos para explorar nas negociações coletivas. Nos casos analisados, porém, a falta de expertise por parte dos sindicalistas, necessária para questionar as informações da administração, os forçava a aceitá-las ou rejeitá-las completamente, sem que conseguissem utilizá-las de modo estratégico. Além disso, por vezes os representantes sindicais consideravam que as informações oriundas dos sistemas contábeis das companhias eram demasiadamente agregadas, tornando-as de pouca utilidade para os propósitos dos sindicatos, sobretudo nas organizações ligadas a uma estrutura corporativa maior.

Ogden e Bougen (1985), por sua vez, apresentam uma visão alternativa sobre as questões que deveriam ser abordadas nas discussões sobre a divulgação de informações contábeis aos sindicatos nos processos de negociações coletivas. Os autores criticam estudos prévios por adotarem, segundo eles, duas premissas: a de que cabe à administração custodiar os processos e estruturas organizacionais, dirigindo e coordenando as atividades da organização rumo a metas acordadas e calcadas nos conceitos de eficiência e racionalidade, se valendo do apoio da contabilidade no desempenho destas tarefas; e a de que os interesses da administração equivalem aos de todas as partes envolvidas, ignorando os antagonismos e conflitos existentes.

Para estes autores, a divulgação de informações aos sindicatos pela administração pode também ser entendida como uma estratégia de exercício do controle gerencial, numa tentativa de persuadir os trabalhadores a adotar uma visão dos processos organizacionais orientada para valores como lucro, racionalidade e eficiência, servindo para evitar que eles se atenham a outros objetivos. Assim, a contabilidade exerceria uma função latente, funcionando como um mecanismo ideológico para propagar e reforçar os valores e propósitos da administração. Ao se assegurarem da divulgação sistemática de informações contábeis, os sindicatos por um lado reduziriam sua desvantagem informacional perante as empresas nos processos de negociação coletiva, advinda da posse de informações exclusivas por parte destas, mas por outro, ao conduzirem negociações baseadas em informações contábeis, estariam aceitando um discurso cuja lógica pertence à administração. Para evitar tal situação, Ogden e Bougen (1985) propõem que os sindicatos desenvolvam critérios alternativos para avaliar o desempenho organizacional, mantendo a integridade e distinção de suas próprias demandas e interesses em relação àqueles oriundos da administração.

Owen e Lloyd (1985), numa revisão crítica de estudos empíricos a respeito do uso de informações contábeis no processo de negociação entre sindicatos e empresas, criticam-nos por terem assumido, sem questionamentos, a ideia de que as demonstrações financeiras seriam potencialmente úteis aos sindicalistas, levando seus autores a desconsiderar possíveis explicações para o baixo grau de utilização destas demonstrações identificado em seus estudos. Tal premissa, assumida com base em considera- 
ções de racionalidade econômica, ignora que as informações contábeis podem assumir um papel de ferramenta ideológica para a propagação e reforço dos valores e propósitos dos administradores que, sendo conflitantes com os dos trabalhadores, pode motivá-los a ignorá-las. Outro aspecto criticado por Owen e Lloyd (1985) nestes estudos é a aparente crença e busca por objetivos universais dos sindicatos, ignorando prováveis distinções entre diferentes categorias de trabalhadores, por exemplo.

Por fim, McBarnet et al. (1993) discutem se as informações contábeis são necessariamente ferramentas capitalistas, ou se podem ser utilizadas de maneira estratégica e contestatória por quem tenha acesso a elas, bem como habilidade e interesse em utilizá-las em benefício próprio. Nos casos investigados pelos autores, os sindicatos utilizavam informações financeiras para uma série de propósitos, tais como negociações salariais, situações de aquisições e fusões de empresas, discussões sobre saúde e segurança no trabalho, remuneração baseada em resultados, campanhas de recrutamento de filiados e para fins de propaganda. A forma de utilização destas informações pelos sindicatos foi classificada pelos autores em três categorias:

- Consensual - as informações contábeis são tidas como objetivas e aceitas tal como interpretadas pela administração. Este uso pode implicar na incorporação ideológica do movimento sindical, com as informações contábeis servindo para legitimar e reforçar os posicionamentos dos administradores;

- Estratégica - as informações são tratadas como objetivas, porém sua interpretação e utilização se dão conforme os interesses do sindicato, o que não implica em concordância com os objetivos dos administradores, tampouco em comprometimento a aceitar as regras por eles impostas. Isto acontece, por exemplo, quando informações contábeis são utilizadas como munição pelo sindicato, a fim de contestar o discurso dos administradores, ou quando estas informações são utilizadas como ferramenta de propaganda para mobilizar as bases sindicais;

- Contestatória - questionam-se ou as decisões tomadas com base nas informações contábeis, ou as próprias políticas contábeis adotadas pela organização. Embora as informações sejam vistas com desconfiança, elas podem fornecer vantagens pragmáticas aos sindicalistas, uma vez que permitam, por exemplo, detectar, expor e questionar a utilização de práticas contábeis questionáveis e que atendam a interesses dos administradores.

Nos diferentes casos analisados, McBarnet et al. (1993) encontraram evidências de uso rotineiro das informações contábeis por parte dos sindicatos, com diversas finalidades e de cada uma das maneiras descritas. Portanto, eles concluem que tais informações podem ser utilizadas de maneira estratégica ou contestatória pelos sindicatos, não devendo ser vistas como ferramentas exclusivas dos administradores. Além disso, os autores destacam ainda o acesso que os empregados têm a informações internas das organizações, o que pode incrementar suas possibilidades de uso estratégico ou contestatório das informações contábeis em comparação a outros grupos de usuários.

Em síntese, tais referências ressaltam a complexidade dos processos de negociações coletivas, rejeitando a ideia de se atribuir comportamentos universais às partes envolvidas. Portanto, cabe à investigação empírica identificar os interesses e estratégias de empresas e sindicatos sob análise. Assim, nosso propósito de compreender como os sindicatos utilizam as informações contidas nos relatórios publicados pelos bancos brasileiros leva em conta a especificidade dos bancários e a multiplicidade de maneiras com que tais informações podem ser utilizadas pelo movimento sindical. 


\section{RESULTADOS}

A Tabela 1 indica a presença de referências a informações extraídas dos relatórios publicados pelos bancos nas matérias da Folha Bancária ao longo de 2012, evidenciando que elas se concentram nas matérias de maior destaque do jornal, sobretudo nas manchetes de capa, das quais mais de $30 \%$ citam tais informações.

Tabela 1: Uso de informações contábeis nas matérias da Folha Bancária em 2012

\begin{tabular}{|c|c|c|c|}
\hline Matéria & Total & \multicolumn{2}{|c|}{ Informações contábeis } \\
\hline Manchete de capa & 117 & 97 & $30,8 \%$ \\
\hline Manchete & 804 & 22 & $12,1 \%$ \\
\hline Editorial & 94 & 1 & $23,4 \%$ \\
\hline Charge & 99 & 2 & $1,0 \%$ \\
\hline Quadro & 774 & $0,3 \%$ \\
\hline
\end{tabular}

Nota. Fonte: Dados da pesquisa.

Já a Figura 2, que apresenta o número de matérias e de ocorrências ao longo do ano de 2012, evidencia que a maior presença destas informações corresponde ao período da campanha nacional da categoria, tradicionalmente conduzida durante o mês de setembro.

Figura 2.:Uso de informações contábeis na Folha Bancária ao longo de 2012

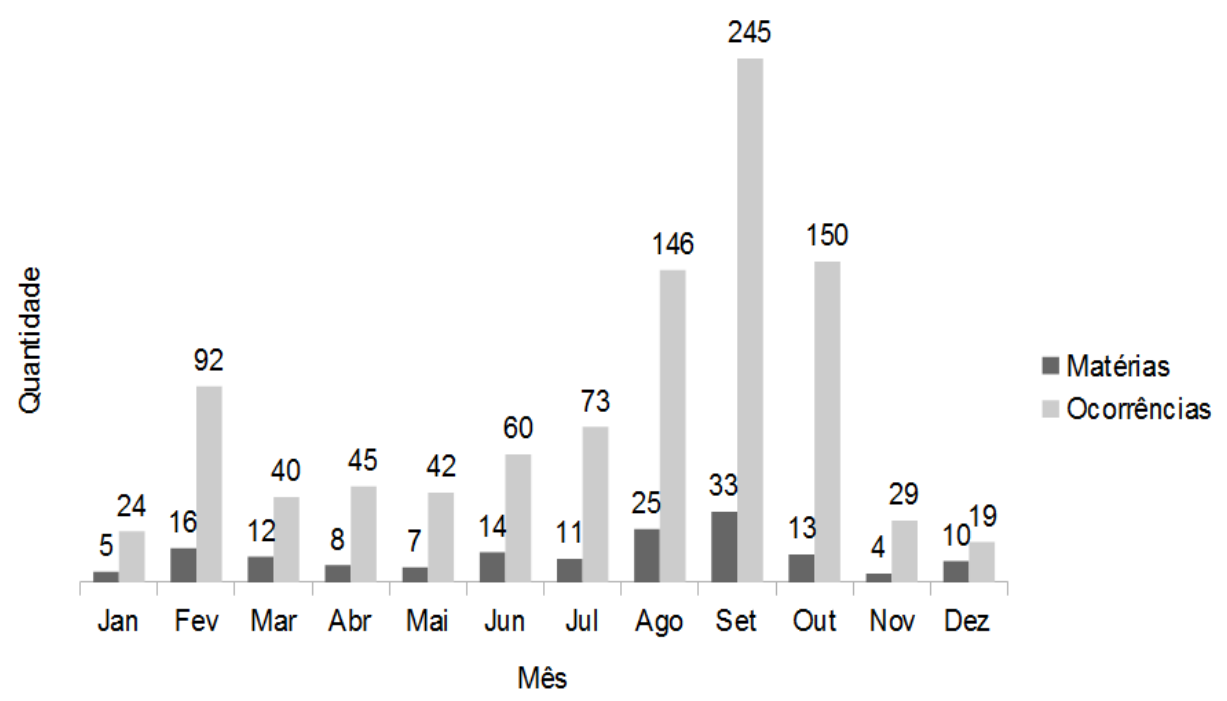

Na Figura 2 são indicados o número de matérias em que foram utilizadas informações rastreáveis nos relatórios publicados pelos bancos brasileiros, e a quantidade de vezes em que elas foram citadas.
Fonte: Dados da pesquisa.

Nos meses de agosto, setembro e outubro, a apresentação dos itens da pauta de reivindicações da categoria e os relatos sobre as reuniões com a FENABAN são geralmente seguidos por uma série de indicadores extraídos dos relatórios publicados pelos bancos, como na matéria de capa da edição 5.570, de 23 de agosto, na qual constam dados relativos a lucro líquido, despesas de pessoal, remuneração dos administradores, participação nos lucros e resultados (PLR) e perdas estimadas com créditos de liquidação duvidosa, iniciando da seguinte maneira:

A rodada de negociação sobre remuneração foi uma queda de braço. De um lado o Comando Nacional dos Bancários cobrando aumento real de salários, PLR maior, valorização do piso e dos auxílios, com estatísticas que mostram o resultado melhor do setor, a cada ano. Do outro, os 
representantes da federação dos bancos com o tradicional "chororô" de que o setor vai lucrar menos. (Bancos vão apresentar proposta no Dia do Bancário, 2012, p.1).

Além do período da campanha nacional, merece destaque também o mês de fevereiro, período de divulgação das demonstrações financeiras anuais dos principais bancos, que foram objeto de análise em notícias especialmente dedicadas a elas. Por si só, as evidências da Tabela 1 e da Figura 2 respondem em grande parte nosso problema de pesquisa, indicando que as demonstrações financeiras publicadas pelos bancos brasileiros são úteis aos representantes do movimento sindical dos bancários, especialmente nos períodos de negociação com a FENABAN.

Convém ter em mente, porém, que a Folha Bancária é um veículo de comunicação entre a diretoria do sindicato e sua base de representação, e portanto opera sobretudo no subprocesso de negociações intraorganizacionais. Apesar disso, como destacam Walton e McKersie (1965), os subprocessos em que classificam tais negociações são inter-relacionados, parecendo-nos razoável supor que as informações citadas no jornal sejam as mesmas utilizadas durante as negociações. A relação das informações contábeis utilizadas com maior frequência no jornal ao longo de 2012 é apresentada na Figura 3.

Figura 3: Informações contábeis utilizadas na Folha Bancária em 2012

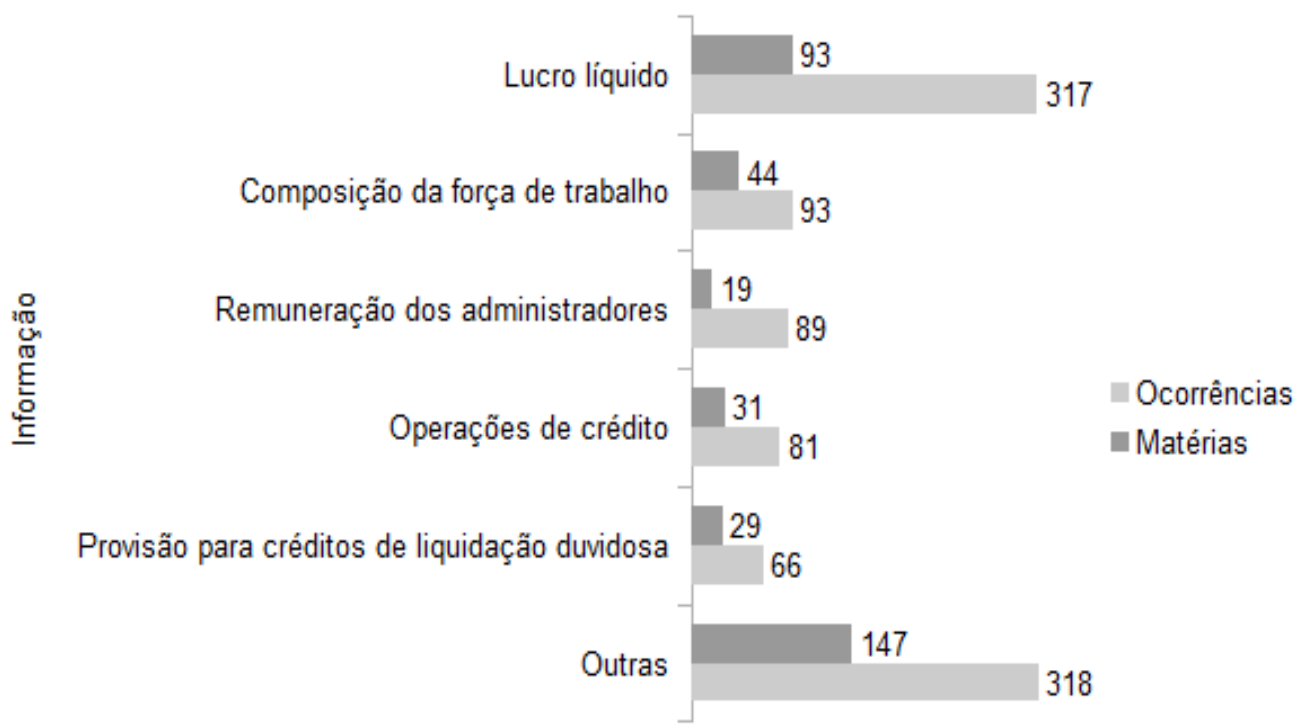

Ocorrência

A Figura 3 apresenta quais informações rastreáveis nos relatórios publicados pelos bancos brasileiros foram utilizadas no jornal Folha Bancária ao longo do ano de 2012. São indicados o número de matérias em que tais informações foram utilizadas e a quantidade de vezes em que elas foram citadas.
Fonte: Dados da pesquisa.

\subsection{MODOS DE USO DAS INFORMAÇÕES CONTÁBEIS}

Das 964 ocorrências que identificamos, 746 delas $(77,4 \%)$ faziam um uso estratégico das informações referenciadas, utilizando-as para justificar as demandas do sindicato. Por exemplo, em matéria onde é relatada a rejeição à proposta inicial de reajuste salarial feita pela FENABAN, sob o sugestivo título de Balanços mostram que grana tem, lê-se o seguinte trecho:

É possível escolher vários indicadores publicados nos balanços do primeiro semestre dos maiores bancos que operam no país. Sejam quais forem, todos comprovam que há recursos mais que suficientes para que a Fenaban melhore a proposta de $6 \%$ feita aos trabalhadores. (Balanços mostram que grana tem, 2012, p.2). 
A informação mais empregada com finalidade estratégica foi o lucro líquido, utilizado principalmente como indicador de capacidade de pagamento, a exemplo da seguinte passagem sobre o início das negociações salariais com a FENABAN:

\begin{abstract}
Trabalhadores valorizaram mesa de negociação, apresentando à Fenaban demandas da categoria com dados que comprovam: os sete maiores bancos lucraram $\mathrm{R} \$ 25,8$ bi só no primeiro semestre e podem pagaraumento real, PLR, piso e auxílios maiores, contratar mais, com melhores condições de trabalho, saúde, segurança e igualdade de oportunidade para todos. (Agora falta a proposta dos bancos, 2012, p.3).
\end{abstract}

A ênfase ao lucro líquido como indicador da capacidade de pagamento é condizente à constatação de Foley e Maunders (1977) de que as informações utilizadas para esta finalidade costumam ser obtidas nas demonstrações financeiras publicadas. Segundo os autores, há duas possíveis razões para isto: uma, que elas sejam usadas simplesmente porque estejam disponíveis e sejam relevantes; e a outra, que os provedores e/ou usuários estejam condicionados a seu uso pela familiaridade. Neste sentido, o baixo uso de informações da demonstração do valor adicionado, que poderia oferecer medidas alternativas de capacidade de pagamento, talvez indique não desinteresse, mas falta de familiaridade quanto a seu conteúdo no meio sindical, pois se trata de uma demonstração cuja exigência de publicação ainda é recente.

Também se destaca o uso estratégico de informações sobre a composição da força de trabalho, sobretudo número de empregados admitidos e demitidos. Em geral, tais informações são extraídas dos formulários de referência ou dos relatórios de sustentabilidade dos bancos, e utilizadas em conjunto com dados sobre o lucro líquido para embasar as demandas da categoria em relação ao nível de emprego.

Além disso, também dos formulários de referência são extraídas informações sobre a remuneração dos administradores, que crescem em destaque durante o período da campanha nacional: das 89 ocorrências registradas, 46 foram no mês de setembro, período em que a categoria esteve em greve. O depoimento do funcionário de um banco durante este período evidencia que tais informações são utilizadas para fortalecer a mobilização dos trabalhadores:

"Vários motivos nos levaram a parar. O valor da PLR, que será menor para muitos bancários este ano, foi uma das principais causas. Principalmente depois que o Sindicato divulgou o quanto ganham os executivos do banco. Ali vimos a desigualdade e a injustiça de forma gritante" (Exemplos da vontade de participar mais, 2012, p.3).

As informações sobre o volume das operações de crédito, por sua vez, são utilizadas principalmente como indicador de produtividade dos bancos, como se depreende na seguinte declaração da senhora Juvandia Moreira, presidenta do Sindicato dos Bancários e Financiários de São Paulo, Osasco e Região: "'As operações de crédito, trabalho eminentemente bancário, cresceram 833,68\% na última década. Os bancários querem sua parte'"' (Remuneração, segurança e igualdade, 2012, p.3).

O uso contestatório das informações contábeis foi identificado em 130 ocorrências (13,5\%), tendo como principal alvo de críticas as práticas contábeis dos bancos em relação à constituição da provisão para créditos de liquidação duvidosa, sob a alegação de que "essa manobra contábil esconde o lucro, uma vez que entra como despesa nos balanços, e não encontra nenhuma justificativa nos percentuais de inadimplência dessas empresas, que permanecem abaixo de 5\%." (Categoria cobra PLR maior, 2012, p.3).

Em apenas 88 ocorrências $(9,1 \%)$ identificamos um uso consensual das informações contábeis. Mas mesmo na maioria destes casos o uso consensual de informações visava subsidiar críticas à gestão das instituições financeiras privadas, recorrendo a dados dos bancos públicos relativos a suas iniciativas de 
redução de juros e tarifas durante 2012, apoiadas pelo movimento sindical, conforme depoimento da presidenta do Sindicato, Juvandia Moreira:

"Há margem para o aumento do crédito. O governo está fazendo a sua parte ao baixar a Selic, os juros e tarifas no Banco do Brasil e na Caixa Federal, mas os bancos privados têm de fazer o mesmo. O setor financeiro privado tem altos lucros e tem de devolver isso à população, cumprindo sua função social." (Ampliar empréstimos é essencial para a economia, 2012, p.1).

Em conjunto, tais evidências sugerem que o movimento sindical dos bancários é capaz de utilizar as informações contábeis a que tem acesso em seu próprio proveito, não dando suporte aos temores expressos na literatura de que o acesso a tais informações o possa prejudicar, embora seja preciso levar em consideração que o setor financeiro tem tradição de alta rentabilidade no Brasil, o que acaba por facilitar o uso estratégico de suas informações contábeis.

\section{CONCLUSÕES}

Ao analisar a utilização, no jornal de um dos principais sindicatos de bancários do país, de informações extraídas dos relatórios publicados pelos bancos brasileiros, nosso estudo evidenciou que tais formações são largamente empregadas, sobretudo de maneira estratégica e no período das negociações coletivas com a entidade patronal. Desta maneira, nossos resultados corroboram a posição de McBarnet et al. (1993), mostrando ser possível que tais informações sejam utilizadas de maneira estratégica ou contestatória pelos sindicatos, não sendo ferramentas a serviço exclusivo dos administradores das organizações.

Há que se considerar, porém, que nossa fonte de evidências se restringe a um veículo de comunicação entre a diretoria e a base de representação do sindicato, e portanto se limita, essencialmente, ao subprocesso das negociações intraorganizacionais. Assim, estudos que incluam evidências obtidas diretamente junto aos atores envolvidos nas negociações entre sindicalistas e representantes das entidades patronais, por exemplo, podem avançar no entendimento dos papéis desempenhados pelas informações contábeis nos demais subprocessos destas negociações, como descrevem Walton e McKersie (1965).

Neste sentido, cremos que duas situações por nós observadas mereçam atenção especial. Primeiramente, analisamos diversos acordos coletivos da categoria quanto à PLR, e em nenhum deles encontramos disposições visando ampliar o acesso dos sindicatos a informações contábeis dos bancos, em que pesem a previsão legal desta possibilidade e a intensa utilização destas informações por nós documentada. Segundo, as informações sobre a composição da força de trabalho dos bancos poucas vezes fazem referência aos relatórios de sustentabilidade, muito embora eles sejam publicados regularmente pelos grandes bancos brasileiros.

Em conjunto, estas situações nos levam a conjecturar que talvez o uso de informações contábeis por nós documentado reflita não uma vontade, mas uma necessidade do movimento sindical. Uma vez que as demonstrações financeiras sejam publicadas pelas organizações, talvez não reste alternativa ao movimento sindical, tendo em vista a autoridade e prestígio social conferidos ao discurso contábil, senão lidar com elas. Seguindo esta linha de raciocínio, o baixo uso de informações oriundas dos relatórios de sustentabilidade refletiria um menor prestígio e autoridade destes relatórios.

Dada a natureza exploratória de nosso estudo, não podemos oferecer respostas fundamentadas a esta questão. Consideramos, contudo, tratar-se de um tema de pesquisa promissor e que tem sido negligenciado na literatura contábil, a qual cada vez mais parece sustentar, ao invés de questionar, a estreita visão que emana dos órgãos reguladores sobre os propósitos e papéis sociais da contabilidade. 


\section{REFERÊNCIAS}

Agora falta a proposta dos bancos. (2012, 23 de agosto). Folha Bancária, p. 3.

Amorim, W. A. C. de, \& Huertas, M., Neto (2011). A Negociação Coletiva do Setor Bancário Brasileiro: Desenvolvimento Recente e Tendências. Boletim Informações FIPE, (374), 26-34.

Ampliar empréstimos é essencial para a economia. (2012, 30 de outubro). Folha Bancária, p. 1.

Balanços mostram que grana tem. (2012, 10 de setembro). Folha Bancária, p. 2.

Bancos vão apresentar proposta no Dia do Bancário. (2012, 23 de agosto). Folha Bancária, p. 1.

Bardin, L. (2011). Análise de Conteúdo. São Paulo: Edições 70.

Burchell, S., Clubb, C., Hopwood, A., Hughes, J., \& Nahapiet, J. (1980). The roles of accounting in organizations and society. Accounting, Organizations and Society, 5(1), 5-27. doi: 10.1016/0361-3682(80)90017-3

Categoria cobra PLR maior. (2012, 11 de setembro). Folha Bancária, p. 3.

Craft, J. (1981). Information disclosure and the role of the accountant in collective bargaining. Accounting, Organizations and Society, 6(1), 97-107. doi:10.1016/0361-3682(81)90024-6

Exemplos da vontade de participar mais. (2012, 20 de setembro). Folha Bancária, p. 3.

Foley, B., \& Maunders, K. (1977). Accounting information disclosure and collective bargaining. London: Macmillan Press.

Fontes, P., Macedo, F., \& Sanches, A. T. (2013). 90 Anos Fortalecendo a Democracia: Bancários de São Paulo - CUT (1923 - 2013). São Paulo: Sindicato dos Bancários e Financiários de São Paulo, Osasco e Região; Atitude.

Gomes, S. M. S. (1998). O uso das demonstrações contábeis como um instrumento orientador das negociações trabalhistas no Brasil (Dissertação de mestrado). Faculdade de Economia, Administração e Contabilidade, Universidade de São Paulo, São Paulo.

Hendriksen, E., \& Van Breda, M. (2007). Teoria da contabilidade (A. Z. Sanvicente, Trad.). São Paulo: Atlas.

ludícibus, S. de. (2004). Teoria da contabilidade (7a ed.). São Paulo: Atlas.

Jackson-Cox, J., Thirkell, J. E. M., \& McQueeney, J. (1984). The disclosure of company information to trade unions: The relevance of the ACAS Code of Practice on Disclosure. Accounting, Organizations and Society, 9(3-4), 253-273. doi:10.1016/0361-3682(84)90011-4

McBarnet, D., Weston, S., \& Whelan, C. J. (1993). Adversary accounting: Strategic uses of financial information by capital and labour. Accounting, Organizations and Society, 18(1), 81-100. doi:10.1016/03613682(93)90026-3

Minella, A. (2007). Maiores bancos privados no Brasil: perfil econômico e sociopolítico. Sociologias, 100-125.

Ogden, S., \& Bougen, P. (1985). A radical perspective on the disclosure of accounting information to trade unions. Accounting, Organizations and Society, 10(2), 211-224. doi:10.1016/0361-3682(85)90017-0

Owen, D. L., \& Lloyd, A. J. (1985). The use of financial information by trade union negotiators in plant level collective bargaining. Accounting, Organizations and Society, 10(3), 329-350. doi:10.1016/03613682(85)90023-6. 
Remuneração, segurança e igualdade. (2012, 14 de agosto). Folha Bancária, p. 3.

Walton, R., \& McKersie, R. (1965). A behavioral theory of labor negotiations: An analysis of a social interaction system. New York: McGraw-Hill.

Young, J. J. (2006). Making up users. Accounting, Organizations and Society, 31(6), 579-600. doi: 10.1016/j.aos.2005.12.005 